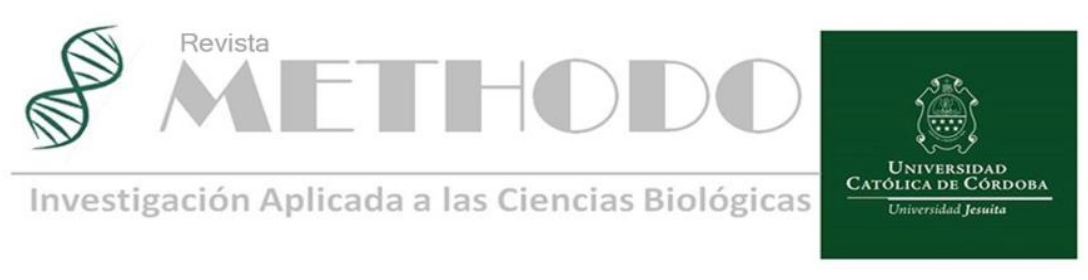

EDITORIAL Methodo 2019;4(4):106-107

https://doi.org/10.22529/me.2019.4(4)01

Solicitado.03 Oct 2019 | Recibido 05 Dic. 2019 | Publicado 27 Dic.2019

\title{
Medicina Traslacional: un nuevo nombre para una antigua práctica
}

\section{Traslational Medicine: A new name for an old practice.}

Cuando se busca en Internet la definición de Medicina Traslacional uno se encuentra con varias posibilidades que a veces se contradicen. Por ello, no existe una definición clara de esta disciplina. Es común encontrar que la Medicina Traslacional es una "ciencia que intenta avanzar rápidamente en la investigación biomédica básica para acelerar el descubrimiento de nuevas herramientas diagnósticas y nuevos tratamientos usando un enfoque multidisciplinar altamente colaborativo", lo cual es real, pero para nada nuevo. También se define como la práctica de transferir el conocimiento científico "del

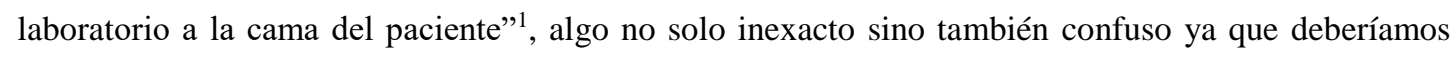
descartar la Medicina Preventiva, la cual se enfoca en individuos sanos para que no lleguen a terminar hospitalizados.

El término Medicina Traslacional se acuñó a fines de los años '90s con la intención de definir políticas que fortalezcan la transferencia de descubrimientos en ciencias básicas a la clínica, y con ello influir en políticas de Salud Pública. Aunque este hecho de por sí fue importante para que los estados dispusieran de más fondos para investigaciones básicas y clínicas, también llevó a presionar para que todo investigador realice Medicina transferible. Fue entonces que el término Medicina Traslacional comenzó a observarse en todo pedido de fondos o subsidios para cualquier tipo de investigación, puesto que para obtener dichos fondos todos forzaban sus proyectos para que sus resultados aparecieran como transferibles al paciente. Para comienzos de este siglo, la Medicina Traslacional se transformó entonces en una moda a la que había que subscribirse.

Sin embargo, no podemos dejar de pensar en los experimentos de laboratorio del químico y microbiólogo Louis Pasteur, que cuando estudiaba la fermentación dio origen al concepto de que gérmenes contagiaban enfermedades, lo que llevó al advenimiento de las vacunas; o del médico Alexander Fleming, quién estudiando el comportamiento de bacterias en un medio de cultivo que resultó contaminado abrió las puertas al descubrimiento de la penicilina y transformó la Medicina Tradicional basada en tratamientos empíricos en la verdadera Medicina Traslacional que nos ha acompañado desde entonces.

Revista Methodo: Investigación Aplicada a las Ciencias Biológicas. Facultad de Medicina. Universidad Católica de Córdoba. Jacinto Ríos 571 Bo Gral. Paz. X5004FXS. Córdoba. Argentina. Tel.: (54) 3514517299

/ Correo: methodo@ucc.edu.ar / Web: methodo.ucc.edu.ar | EDITORIAL Methodo 2019;4(4):106-107 
Por ello, la Medicina Traslacional actual es solo un nuevo intento de mostrar que sin investigación básica de calidad no podrá haber productos o metodologías de calidad para ser utilizados no solo "en la cama del paciente", sino antes de que el paciente llegue a ese estado.

Lo destacable de la historia de la Medicina y de las Ciencias en general es que el trabajo del investigador básico es revalorizado, su interacción con los investigadores clínicos se ve aumentada y la búsqueda de las bases moleculares de los estados de salud y enfermedad llevan a los investigadores clínicos a buscar en las ciencias biomédicas básicas su sustento para mejorar la labor médica. Esta interacción constante hace que los resultados de laboratorio nutran a la clínica y que los clínicos nutran a los investigadores básicos con nuevas preguntas o preocupaciones que requieren respuestas innovadoras.

El trabajo conjunto a lo largo de la historia ha demostrado que los avances son constantes y evidentes. Los ejemplos de Bernardo Houssay (Farmacéutico y Médico; Premio Nobel en Medicina o Fisiología); Luis Leloir (Médico; Premio Nobel en Química), y César Milstein (Bioquímico; premio Nobel en Medicina o Fisiología) ${ }^{2}$ demuestran que no importa el título universitario que se ostente, sino la capacidad, la inteligencia, la creatividad y la solidaridad con el prójimo para cambiar la realidad para un mayor bienestar de la Sociedad.

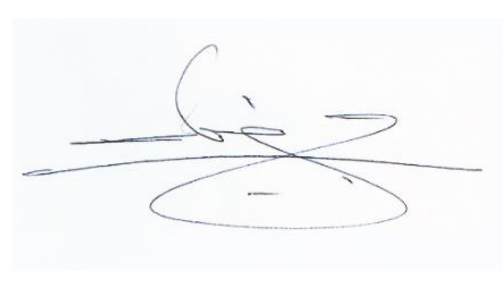

Dr. Hugo D. Lujan

Laboratorio de Bioquímica y Biología Molecular. Facultad de Ciencias de la Salud. Universidad Católica de Córdoba (UCC) y Centro de Investigación y Desarrollo en Inmunología y Enfermedades Infecciosas (CIDIE-CONICET/UCC). Av. Armada Argentina 3555. CP X5016HDK. Córdoba. Argentina. 